\title{
The Relationship among Information and Communication Technologies and GDP in Middle East Countries: Panel Cointegration Approach
}

\author{
Mohsen Mehrara ${ }^{1, a}$, Alireza Ebrahimian ${ }^{2, b}, Z^{2}$ abihallah Falahati ${ }^{1, c}$ \\ ${ }^{1}$ Faculty of Economics, University of Tehran, Tehran, Iran \\ 2Department of Regulation, Planning \& Economics Affairs, Ministry of Energy, Iran \\ a-cE-mail address: mmehrara@ut.ac.ir , ebrahiimian@yahoo.com , zabihfalahati@ut.ac.ir
}

\begin{abstract}
This paper studies the causality relationship between Foreign Direct Investment and Information and Communication Technologies based on panel data covering Middle East countries during the period 1990-2010. The empirical results support of a short-run cointegration relationship after allowing for the heterogeneous country effect. The long-run relationship is estimated using a full-modified OLS. Pedroni's heterogeneous panel cointegration test reveals have long-run equilibrium relationship between FDI and economic growth. The analysis of results indicate that the growth contribution of ICT and FDI was quite low for these countries. The econometric results showed a positive and significant impact of ICT and FDI in these countries.
\end{abstract}

Keywords: Forign Direct Investment; Information and Communication Technologies; Growth; Economic Development

\section{INTRODUCTION}

The growth of international production is driven by economic and technological forces. It is also driven by the ongoing liberalization of Foreign Direct Investment and trade policies. The rapidly rising level of economic integration, stimulated by advances in Information and Communication Technology (ICT), renders technology adoption, coming from foreign developed countries, a matter of great importance for economic growth and productivity improvement. Foreign Direct Investment is considered, among others, an important channel for technology diffusion, which in turn raises the host country's productivity growth. On the other hand, the new 'information economy' of the past decades is associated with increased diffusion of ICTs, which are expected to deliver higher productivity gains and enhanced growth (Dimelisa and Papaioannou, 2010).

However, FDI provides much needed resources to developing countries such as capital, technology, managerial skills, entrepreneurial ability, brands, and access to markets. These are essential for developing countries to industrialize, develop, and create jobs attacking the poverty situation in their countries (Louzi. B. Mohammed and Abadi, Abeer, 2011). As a result, most developing countries recognize the potential value of FDI and have liberalized their investment regimes and engaged in investment promotion activities to attract various countries. Fewer studies have been conducted at the macro or international level given the lack of long time- 
series data on FDI, ICT and other relevant country characteristics. (Dimelisa and Papaioannou, 2010).

Existing empirical evidence, in contrast with more settled theoretical evidence, shows mixed results about the relationship between FDI and economic growth of the host countries, and the determinants of FDI. Several reasons may be advanced to explain such disparity of empirical results. To mention a few, first, tests are traditionally conducted using data sets usually belong to heterogeneous groups of countries. Second, previous studies have used a variety of theoretical models. Third, empirical studies have usually implemented a number of different econometric techniques in testing and estimation (Al-Iriani, Mahmoud and Fatima AlShamsi, 2008).

In this paper, we intend to examine the FDI and ICT Effects on Productivity Growth: A Comparative Analysis of Developing and Developed Countries according to Dimelisa, and Papaioannou (2010) article.

The rest of this article is organized as follows. The next section introduces the econometric specification. In the penultimate section, the econometric results are shown and discussed. Finally, the last section concludes.

\section{ECONOMETRIC APPROACH}

To capture FDI and ICT effects on productivity growth, a production function is specified with several types of inputs. The present study considers the accumulation of FDI or ICT as special types of knowledge and technology capital introduced in the production process. Consequently, the regression analysis will be carried on by decomposing the overall effect of total capital to that of its individual domestic, foreign and ICT components.

Thus, following the paradigm of Hall and Mairesse (1995), Dimelisa and Papaioannou (2010) an aggregate Cobb-Douglas production function is specified, which incorporates four inputs, domestic capital (K), labor (L), foreign capital (F) and ICT capital:

$$
Y_{i t}=A_{i t} e^{c t}\left(K_{i t}\right)^{\alpha}\left(L_{i t}\right)^{\beta}\left(F_{i t}\right)^{\gamma}\left(I C T_{i t}\right)^{\delta} e^{u_{i t}}
$$

where the subscripts of $i$ and $t$ denote country and year, respectively; $Y$ measures gross output of each country; $\mathrm{A}$ is an index of technical progress; while $\mathrm{K}$ and $\mathrm{F}$ are taken to represent nonICT capital. Parameters $\alpha, \beta, \gamma$ and $\delta$ are the elasticities of domestic capital, labor, foreign capital and ICT with respect to output and finally $u_{i t}$ is the error term capturing unobserved variations between countries and over time. After taking logarithms and following the assumption of constant returns to scale, the level of output per worker can be expressed as a function of domestic, foreign and ICT capital to labor ratios (Dimelisa, and Papaioannou, 2010):

$\ln \left(y_{i t}\right)=c t+\ln \left(A_{i t}\right)+\alpha \ln \left(k_{i t}\right)+\gamma \ln \left(f_{i t}\right)+\delta \ln \left(i c t_{i t}\right)$

where small case letters denote figures per worker. Writing (2) in first differences we obtain the following growth regression:

$\Delta \ln \left(y_{i t}\right)=c t+\ln \left(\Delta A_{i t}\right)+\alpha \ln \left(\Delta k_{i t}\right)+\gamma \ln \left(\Delta f_{i t}\right)+\delta \ln \left(\Delta i c t_{i t}\right)$

Following common practice in the growth literature, equation (3) is further augmented by the lagged level of the dependent variable. According to the neoclassical growth model, a 
negative impact is expected, implying that more developed economies are closer to their steady state equilibrium and display lower growth rates (Dimelisa and Papaioannou, 2010).

\section{ECONOMETRIC METHODS - ENDOGENEITY ISSUES}

When dealing with panel data growth regressions, the standard practice is to use either the fixed or the random effect estimator, depending on the correlation between the cross section effect and the explanatory variables. Nevertheless, their use might not always provide precise estimates in the presence of endogenous variables (Chowdhury and Mavrotas, 2006). The inclusion of the lagged level of the dependent variable in the empirical specification of model 3 may also create endogeneity problems through its relation to the dependent variable, causing correlation with the error term (Dimelisa and Papaioannou, 2010).

\section{1. A Growth Accounting Approach}

Given the construction of ICT stocks, it would be interesting to perform a preliminary growth accounting exercise and analyze the relative contribution of each production factor. In this way, the growth accounting analysis can motivate the econometric analysis that constitutes the main part of this study. We start with the production function specified in (1). In growth accounting we assume that constant returns to scale are present, so that $\alpha+\beta+\gamma+\delta=1$. After taking logarithms, differentiating both sides of equation (1) and accepting the hypothesis of constant returns to scale, we obtain (Dimelisa and Papaioannou, 2010):

$\hat{y}_{t}=\hat{a}_{t}+a \hat{k}_{t}+\gamma \hat{f}_{t}+\delta \widehat{\iota c t}_{t}+(1-a-\gamma-\delta) \hat{l}_{t}$

where the hats above letters denote variables in logarithmic differences. In the above equation, output growth is decomposed to TFP growth $(\hat{a})$, and a weighted average of domestic $(\hat{k})$, foreign $(\hat{f})$, ict $(\widehat{l c t})$ capital and labor $(\hat{l})$ growth.

\section{2. The panel unit roots test}

In order to investigate the possibility of panel cointegration, it is first necessary to determine the existence of unit roots in the data series. For this study we have chosen the Im, Pesaran and Shin (IPS, hereafter), which is based on the well-known Dickey-Fuller procedure. Investigations into the unit root in panel data have recently attracted a lot of attention. Levine and Lin, (1993) proposes a panel-based ADF test that restricts parameters $\gamma_{i}$ by keeping them identical across cross-sectional regions as follows:

$$
\Delta y_{i t}=\alpha_{i}+\gamma_{i} y_{i t-1}+\sum_{j=1}^{k} \alpha_{j} \Delta y_{i t-j}+e_{i t}
$$

where $\mathrm{t}=1, \ldots, \mathrm{T}$ time periods and $\mathrm{i}=1, \ldots \mathrm{N}$ members of the panel. LL tests the null hypothesis of $\gamma_{i}=\gamma=0$ for all $\mathrm{i}$, against the alternate of $\gamma_{1}=\gamma_{2} \ldots=\gamma<0$ for all $\mathrm{i}$, with the test based on statistics $t_{\gamma}=\hat{\gamma} /$ s.e. $(\hat{\gamma})$. One drawback is that $\mathrm{c}$ is restricted by being kept identical across regions under both the null and alternative hypotheses (Lee, Chien-Chiang, 2005).

For the above reason, IPS (1997) relax the assumption of the identical first-order autoregressive coefficients of the LL test and allow $\gamma$ to vary across regions under the alternative hypothesis. IPS test the null hypothesis of $\gamma_{i}=0$ for all $\mathrm{i}$, against the alternate of 
$\gamma_{i}<0$ for all $\mathrm{i}$. The IPS test is based on the mean-group approach, which uses the average of the $t_{\gamma_{i}}$ statistics to perform the following $\bar{Z}$ statistic:

$\bar{Z}=\sqrt{N}(\bar{t}-E(\bar{t})) / \sqrt{\operatorname{Var}(\bar{t})}$

where $\bar{t}=\left(\frac{1}{N}\right) \sum_{i=1}^{N} t_{\gamma_{i}}$, the terms $\mathrm{E}(\bar{t})$ and $\operatorname{Var}(\bar{t})$ are, respectively, the mean and variance of each $t_{\gamma_{i}}$ statistic, and they are generated by simulations and are tabulated in IPS (1997). Hadri (2000) argues differently that the null should be reversed to be the stationary hypothesis in order to have a stronger power test. Hadri's (2000) Lagrange multiplier (LM) statistic can be written as (Lee, Chien-Chiang, 2005):

$$
\widehat{L M}=\frac{1}{N \sum_{i=1}^{N}\left(\frac{\frac{1}{T^{2}} \sum_{t=1}^{T} S_{i t}^{2}}{\widehat{\sigma}_{\varepsilon}^{2}}\right)} S_{i t}=\sum_{j=1}^{t} \widehat{\varepsilon_{l \jmath}}
$$

where $\hat{\sigma}_{\varepsilon}^{2}$ is the consistent Newey and West (1987) estimate of the long-run variance of disturbance terms.

The next step is to test for the existence of a long-run cointegration among GDP and the independent variables using panel cointegration tests suggested by Pedroni (1999 and 2004). The panel cointegration tests Pedroni (1999) considers the following time series panel regression.

$y_{i t}=\alpha_{i t}+\delta_{i t} t+X_{i} B_{i}+e_{i t}$

where $y_{i t}$ and $X_{i t}$ are the observable variables with dimension of $(N * T) \times 1$ and $(N * T) \times$ $m$, respectively. He develops asymptotic and finite-sample properties of testing statistics to examine the null hypothesis of non-cointegration in the panel. The tests allow for heterogeneity among individual members of the panel, including heterogeneity in both the long-run cointegrating vectors and in the dynamics, since there is no reason to believe that all parameters are the same across countries (Lee, Chien-Chiang, 2005).

Table 1. Panel unit root tests.

\begin{tabular}{|c|c|c|c|}
\hline \multirow{2}{*}{ Variable } & LL & IPS & Hadri \\
\cline { 2 - 4 } & $\begin{array}{c}\text { Time fixed } \\
\text { effects }\end{array}$ & $\begin{array}{c}\text { Time fixed } \\
\text { Effects }\end{array}$ & $\begin{array}{c}\text { Time fixed } \\
\text { effects }\end{array}$ \\
\hline Y & 0.58 & -1.62 & 4.64 \\
\hline ICT & -2.34 & -2.52 & 3.68 \\
\hline FDI & 2.98 & -1.33 & 4.11 \\
\hline
\end{tabular}

$\Delta$ denotes first differences. All variables are in natural logarithms. Data Source: World Development Indicators (2011).

Two types of tests are suggested by Pedroni. The first type is based on the within dimension approach, which includes four statistics. They are panel $v$-statistic, panel $\rho$ statistic, panel PP-statistic, and panel ADF-statistic. These statistics pool the autoregressive coefficients across different members for the unit root tests on the estimated residuals. 
Table 1 presents the panel unit root tests. At a 5\% significance level, all statistic of the level model confirm that all series have a panel unit root.

The second test by Pedroni is based on the between-dimension approach, which includes three statistics. They are group $\rho$ statistic, group PP-statistic, and group ADF-statistic. These statistics are based on estimators that simply average the individually estimated coefficients for each member. Following Pedroni (1999), the heterogeneous panel and heterogeneous group mean panel cointegration statistics are calculated as follows.

Panel $v$-statistic:

$$
Z_{v}=\left(\sum_{i=1}^{N} \sum_{t=1}^{T} \hat{L}_{11 i}^{-2} \hat{e}_{i t-1}^{2}\right)^{-1}
$$

Panel $\rho$-statistic:

$$
Z_{\rho}=\left(\hat{\sigma}^{2} \sum_{i=1}^{N} \sum_{t=1}^{T} \hat{L}_{11 i}^{-2} \hat{e}_{i t-1}^{2}\right)^{-1 / 2} \sum_{i=1}^{N} \sum_{t=1}^{T} \hat{L}_{11 i}^{-2}\left(\hat{e}_{i t-1} \Delta \hat{e}_{i t}-\hat{\lambda}_{i}\right)
$$

Panel ADF-statistic:

$$
Z_{t}^{*}=\left(\hat{s}^{* 2} \sum_{i=1}^{N} \sum_{t=1}^{T} \hat{L}_{11 i}^{-2} \hat{e}_{i t-1}^{* 2}\right)^{-1 / 2} \sum_{i=1}^{N} \sum_{t=1}^{T} \hat{L}_{11 i}^{-2} \hat{e}_{i t-1}^{*} \Delta \hat{e}_{i t}^{*}
$$

Group $\rho$-statistic:

$$
\tilde{Z}_{\rho}=\sum_{i=1}^{N}\left(\sum_{t=1}^{T} \hat{e}_{i t-1}^{2}\right)^{-1} \sum_{t=1}^{T}\left(\hat{e}_{i t-1} \Delta \hat{e}_{i t}-\hat{\lambda}_{i}\right)
$$

Group PP-statistic:

$$
\tilde{Z}_{t}=\sum_{i=1}^{N}\left(\hat{\sigma}^{2} \sum_{t=1}^{T} \hat{e}_{i t-1}^{2}\right)^{-1 / 2} \sum_{t=1}^{T}\left(\hat{e}_{i t-1} \Delta \hat{e}_{i t}-\hat{\lambda}_{i}\right)
$$

Group ADF-statistic:

$$
\tilde{Z}_{t}^{*}=\sum_{i=1}^{N}\left(\sum_{t=1}^{T} \widehat{s}_{l}^{2} \hat{e}_{i t-1}^{* 2}\right)^{-1 / 2} \sum_{t=1}^{T}\left(\hat{e}_{i t-1}^{*} \Delta \hat{e}_{i t}^{*}\right)
$$

Here, $\hat{e}_{i t}$ is the estimated residual from Eq. (4) and $\hat{L}_{11 i}^{2}$ is the estimated long-run covariance matrix for $\Delta \hat{e}_{i t}$. Similarly, $\hat{\sigma}_{i}^{2}$ and $\widehat{s}_{l}^{2}\left(\hat{s}_{i}{ }^{* 2}\right)$ are, respectively, the long-run and contemporaneous variances for individual $i$. The other terms are properly defined in Pedroni (1999) with the appropriate lag length determined by the Newey-West method. All seven tests are distributed as being standard normal asymptotically. This requires a standardisation based on the moments of the underlying Brownian motion function. The panel m-statistic is a onesided test where large positive values reject the null of no cointegration. The remaining statistics 
diverge to negative infinitely, which means that large negative values reject the null. The critical values are also tabulated by Pedroni (1999) (Lee, Chien-Chiang, 2005).

Table 2. Panel cointegration tests.

\begin{tabular}{|c|c|c|}
\hline & No time effects & Time fixed effects \\
\hline Panel variance & 1.19 & 1.50 \\
\hline Panel $\rho$ & -1.34 & 0.62 \\
\hline Panel PP & -1.42 & -1.74 \\
\hline Panel ADF & -2.11 & -2.24 \\
\hline Group $\rho$ & -0.87 & 1.66 \\
\hline Group PP & -1.42 & -1.27 \\
\hline Group ADF & -2.26 & -2.62 \\
\hline
\end{tabular}

Statistics are asymptotically distributed as normal. The variance ratio test is rightsided, while the others are left-sided.

Table 2 reports the panel cointegration estimation results. For the all statistics significantly we cannot reject the null of no cointegration. Thus, it cannot be seen that the GDP, ICT, and FDI move together in the long run. That is, there is not a long-run steady state relationship between ICT and GDP for a cross-section of countries. The next step is an estimation of such a relationship.

In the presence of unit root variables, the effect of superconsistency may not dominate the endogeneity effect of the regressors if OLS is employed. Pedroni (2000) shows how FMOLS can be modified to make an inference in being cointegrated with the heterogeneous dynamic. In the FMOLS setting, non-parametric techniques are exploited to transform the residuals from the cointegration regression and can get rid of nuisance parameters (Lee, ChienChiang, 2005).

\section{EMPIRICAL INVESTIGATION}

Our study uses annual time series for Middle East countries. The empirical period depends on the availability of data, where the time period used is 1990-2010. All variables used are in natural logarithms. Given that our variables are cointegrated, the next step is estimation of the long-run relationship. The OLS estimator is a biased and inconsistent estimator when applied to cointegrated panels. Therefore, we estimate the long-run relationship using FMOLS approach suggested by Pedroni $(2000,2001)$. The FMOLS estimator not only generates consistent estimates of the $\beta$ parameters in small samples, but it controls for the likely endogeneity of the regressors and serial correlation. The panel FMOLS estimator for the coefficient $\beta$ is given as follows:

$B_{N T}^{*}=N^{-1} \sum_{i=1}^{N}\left(\sum_{t=1}^{T}\left(X_{i t}-\overline{X_{i}}\right)^{2}\right)^{-1}\left(\sum_{t=1}^{T}\left(X_{i t}-\overline{X_{i}}\right) Y_{i t}^{*}-T \tau_{i}\right)$ 
Table 3 reports the results of the individual and panel FMOLS. The panel estimators with and without common time dummies are shown at the bottom of the table. We can see from the table that the estimated coefficient of the FDI and ICT are all positive and statistically significant. These findings provide strong evidence that FDI has a positive effect on economic growth.

Table 3. Full modified OLS estimates (dependent variable is Y).

\begin{tabular}{|c|c|}
\hline Dependent Variable: Y & GDP \\
\hline ICT & $2.14(3.13)$ \\
\hline FDI & $3.21(2.14)$ \\
\hline Panel (without time dummies) & $0.56(4.12)$ \\
\hline Panel (with time dummies) & $0.42(5.14)$ \\
\hline
\end{tabular}

Data Source: World Development Indicators (2011).

\section{CONCLUSIONS}

This paper investigates the long-run relationship between the FDI, ICT and economic growth for a panel of Middle East countries over the period 1990-2010 by using recently developed panel data unit root tests and Pedroni panel data cointegration techniques. The IPS panel unit root test results show that the series in the panel are integrated of the order one. The Pedroni panel cointegration test results based on seven test statistics show that there is a longrun relationship between economic growth and the FDI. The growth accounting results indicate that the contribution of ICT and FDI was quite low for this countries. The econometric results confirm that the growth impact of ICT is positive and significant in these countries, the effect being larger among developing countries. A positive and significant effect was also found for FDI in the panel of countries. Policies that foster macroeconomic stability, increased investment in capital and productive spending, and therefore improve economic growth, would also have an important effect on FDI in the long run.

\section{References}

[1] Al-Iriani, Mahmoud and Fatima Al-Shamsi. (2008) Foreign Direct Investment and Economic Growth in the GCC Countries: A Causality Investigation Using Heterogeneous Panel Analysis.

[2] Barro, R. (1991) Economic growth in a cross section of countries. Quarterly Journal of Economics 106(2): 407-433.

[3] Barro, R. and Sala-i-Martin, X. (1995) Economic Growth. New York: McGraw-Hill.

[4] Chowdhury, A. and Mavrotas, G. (2006) FDI and growth: What causes what? The World Economy 29(1): 9-19. 
[5] Dimelisa, P.S and Papaioannou, K.S (2010) FDI and ICT Effects on Productivity Growth: A Comparative Analysis of Developing and Developed Countries. European Journal of Development Research 22(2): 79-96.

[6] Engle, R., Granger, C., 1987. Cointegration and error correction: representation, estimation, and testing. Econometrica 55, 257-276.

[7] Hadri, K., 2000. Testing for stationarity in heterogeneous panel data. Econometrics Journal 3(1), 148-161.

[8] Hall, B.H. and Mairesse, J. (1995) Exploring the relationship between R\&D and productivity in French manufacturing firms. Journal of Econometrics 65(1): 263-293.

[9] Harris, R. (1995) Communication costs and trade. Canadian Journal of Economics 28(s1): 46-75.

[10] Im, K.S., Pesaran, M.H., Shin, Y., (1997). Testing for unit roots in heterogeneous panels. Working paper. University of Cambridge.

[11] IMF (2003). International Financial Statistics. Washington DC: International Monetary Fund.

[12] Levine, A., Lin, C.F., (1993). Unit root tests in panel data: asymptotic and finite sample properties, working paper. Department of Economics, University of California at San Diego.

[13] Louzi B. Mohammed and Abadi, Abeer (2011). The impact of foreign direct investment on economic growth in Jordan. IJRRAS 8(2): 253-259.

[14] Pedroni, P. (1999). Critical values for cointegration tests in heterogeneous panels with multiple regressors. Oxford Bulletin of Economics and Statistics 61(2), 653-670.

[15] Pedroni, P., (2000). Full modified OLS for heterogeneous cointegrated panels. Nonstationary Panels Panel Cointegration and Dynamic Panels, Advances in Econometrics, 15(1): 93-130.

[16] Tiwari, M. (2008) ICTs and poverty reduction: User perspective study of rural Madhya Pradesh, India. The European Journal of Development Research 20(3): 448-461.

[17] World Bank (2011). Global Development Finance. Washington DC. 